\title{
Effect of Isometric and Isotonic Exercise Program on Increased Strength of Quardriceps Muscles in Osteoarthritis Patients in Singgasana Rama Physiotherapy Clinic Blitar
}

\author{
Irwan Syahputra ${ }^{1}$, \\ Nurwijayanti ${ }^{2}$ \\ ${ }^{1}$ Mardi Waluyo General \\ Hospital, Blitar \\ ${ }^{2}$ Master of Public Health, \\ Postgraduate, IIK Strada \\ Indonesia \\ Email: \\ irwansyahputra114@gmail.com
}

Received : October $4^{\text {nd }} 2021$

Accepted : October $15^{\text {rd }} 2021$

Published : November $27^{\text {th }} 2021$

\begin{abstract}
Background: Osteoarthritis is a disease of the joints that can cause disability and is progressive in the joints which cause changes in the water content, proteoglycin content, and collagen in the joints. One of the ways to improve functional ability in osteoarthritis cases is to use isotonic and isometric training exercise. Pain is a clinical symptom of knee osteoarthritis, limiting movement due to pain over time will cause rehabilitation problems such as impaired flexibility and stability, reduction of muscle mass (atrophy). Mild and moderate intensity quadriceps strength training is effective at achieving optimal muscle strength and function without causing significant muscle damage.

Destination: The purpose of this study was to analyze the effect of isotonic and isometric exercises on muscle strength.

Research methods: This study uses a pre-experimental research type using "One Group Pre - test and Post - Test". This research has carried out the first observation (pretest) so that researchers can test the changes that occur after the treatment, and the control group.

Result: with the Wilcoxon signed rank test test the isometric and isotonic groups had $\mathrm{p}=0.000$ while the control group had a significance value of $p=1,000$; and the 3 groups test has different values, namely: isotonic exercise has a value of 27.67; isometric; 28.60; and control 12.73. The conclusion that can be concluded that the value of isometric training has the highest value, namely 28.60 which means it is the most effective exercise to increase the value of Manual Muscle Testing.
\end{abstract}

Conclusion: There is an effect of giving isometric and isotonic exercises in strengthening the quadriceps muscles.

Keywords: quadriceps, osteoarthitis, manual muscle training, isotonic, isometric

Copyright @ 2021 IIK STRADA Indonesia All right reserved.

This is an open-acces article distributed under the terms of the Creative Commons Attribution-ShareAlike 4.0 International License.

\section{INTRODUCTION}

Osteorthritis (OA) is a degenerative joint disease which is a disorder of the cartilage (joint cartilage) which is characterized by clinical, histological, and radiological changes (Kuntono, 2011). Osteoarthritis is a disease of the joints that can cause disability and is progressive in the joints which cause changes in the water content, proteoglycin content, and collagen in the joints. Genu 
osteoarthritis is a pathological condition that involves all tissues in the joint, including articular cartilage, subchondral bone, ligaments, periarticular structures, where there is damage to joint cartilage caused by the formation of osteophytes that irritate the synovial membrane and pinch polymodal nerve endings. So that people with osteoarthritis genu experience tenderness and movement disorders which result in blocked joint motion mechanisms and functional limitations when walking, standing and sitting. Patients will also have difficulty doing daily living activities (Pranatha, 2013). The role of physiotherapy is very important to help patients with osteorthritic knees to reduce pain and improve stability of the knee joint by increasing the strength of the quadriceps muscles. The management of physiotherapy in patients with osteoarthritis are various greatly from patient to patient, but in the case of research using isotonic training with the resistance training method an effort to reduce pain due to the muscle factor osteorathiritis of the knee. Physiotherapists as health professionals have high abilities and skills to develop, prevent, treat and restore a person's movement and function. The role of physiotherapy that can be done to improve functional abilities in cases of osteoarthritis genu is by using isotonic and isometric training modalities and then measuring the level of functional ability using (Western Ontario and McMaster Universities Osteoarthritis Index; WOMAC index) (Ackerman, 2011). Isotonic exercise, which is a type of dynamic exercise with muscle contractions that use constant weights and changes in muscle length in the range of motion of the joints. Exercise therapy is used to reduce pain and maintain muscle strength and range of motion, namely isometric exercises. Isometric exercises are perhaps the most precise and easy for the patient to understand and are safe to do at home because they do not require or minimal equipment. Furthermore, isometric exercises do not cause intraarticular inflammation, pressure, and bone damage (Anwer and Alghadir, 2014).

Based on the results of research conducted by Azka (2014) states that light and moderate intensity quadriceps strength training is effective in achieving optimal muscle strength and function without causing significant muscle damage. According to research conducted by Meiliasary (2013). The results showed that treatment using isotonic exercises with resistance training method was very influential in reducing the pain value than the control group, where some samples experienced increased pain. There is an effect of isotonic training with the resistance training method on pain due to muscle factors in knee osteoarthritis. Rika's research results (2005).

\section{RESEARCH METHODS}

The research approach that used in this research is a quantitative approach. Research is a plan and structure of investigation that is structured in such a way that the research will be able to obtain answers to its research questions. The plan is a comprehensive scheme that includes a research program (Kerlinger, 2012). The research design is made to make researchers able to answer the researcher's questions as validly, objectively, as quickly and economically as possible (Bhisma, 2010). The research design used in this study was experimental research. This study uses a preexperimental research type using "One Group Pre - test and Post - Test". This research has carried out the first observation (pretest) so that the researcher can test the changes that occur after the treatment, but in this design there is no control group (comparison). In this study, only one research group would be given isometric and isotonic exercises without a control group (Riyanto, 2011).

The research sample was taken from December 2020 to January 2021 who came to the Singgasana Rama Blitar clinic. Anamnesis and physical examination were carried out in general and specifically for the knee joint, to look for inclusion and exclusion criteria. Respondents who met the criteria were given an explanation and if they were willing to take part in the research, the respondents were asked to sign an informed consent. The process of taking sample data at the clinic took two months to follow the exercise program which was carried out 3 times per week for 4 weeks.

Retrieval of quadriceps muscle strength data using manual muscle testing, for all samples carried out by the same person, namely the researcher himself. Prior to the assessment of muscle strength, a warm-up was carried out by stretching the extensor and knee flexor muscle groups, then the researcher explained and demonstrated. Research respondents were grouped into 3 (three) groups, namely the isometric exercise group, isotonic exercise group and the control group. Then, the groups were compared before and after being given the intervention for 4 weeks. 


\section{RESULTS}

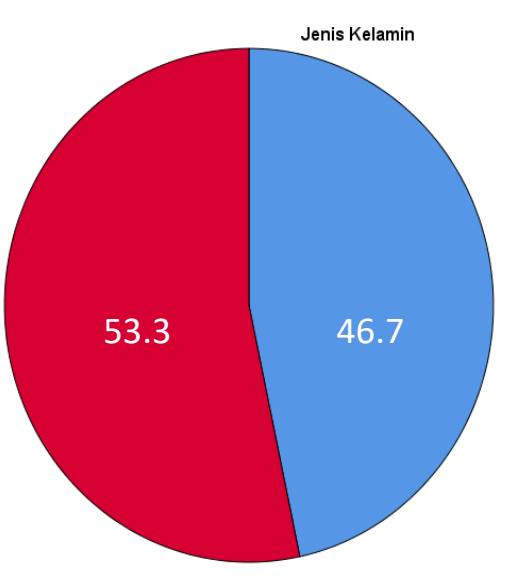

Diagram 1: Gender of Respondent

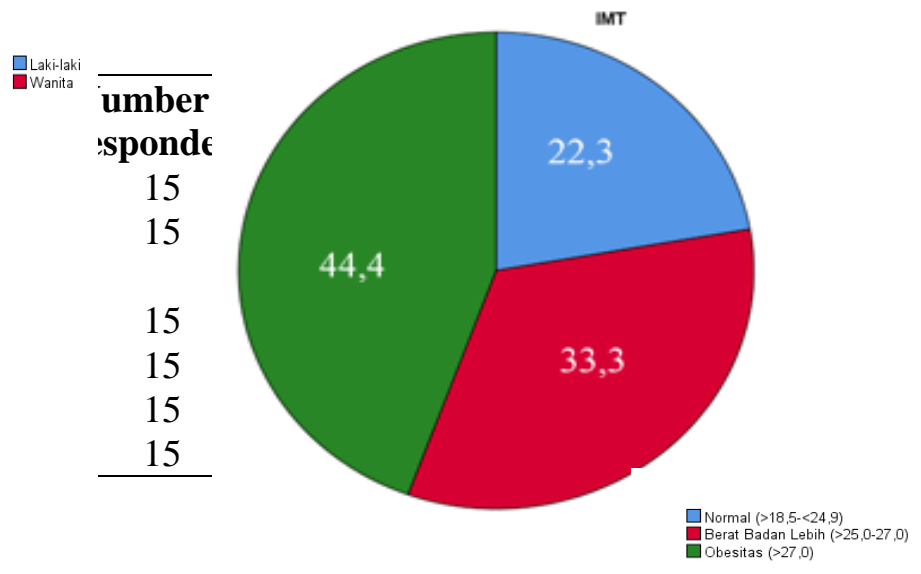

Diagram 2: BMI of respondents

Characteristics of respondents based on gender in diagram 1 at the Singgasana Rama Physiotherapy Clinic in this study, based on the diagram above, there are 21 men (46.7\%) and 24 women (53.3\%). So it can be concluded that knee Osteoarthritis is mostly suffered by women and has a high risk of experiencing knee Osteoarthritis. Characteristics of respondents based on body mass index based on diagram 2 in the Physiotherapy Clinic of Singgasana Rama in this study are the distribution of body mass index data in this study is normal, there are 10 people $(22.2 \%)$, overweight there were 15 people (33.3\%), and obese there were 20 people (44.4\%). The conclusion that can be drawn is that most of the respondents are obese.

Based on the Manual Muscle Training value before and after the intervention was given, there was an average value after the isometric exercise was 4.53. After being given isotonic intervention there is an average value of 4.47. In the control group there was no change in the average value, namely 3.47 . It can be concluded that there is an increase in the isometric and isotonic groups. So that there is an increase in the provision of isometric and isotonic exercises.

Table 1: Isometric, isotonic and control interventions 
Table 2: Normality test

\begin{tabular}{cccc}
\hline \multicolumn{4}{c}{ Shapiro-Wilk } \\
& Statistics & Df & Sig. \\
Isometric pre test & 0,000 & 7 & 0,000 \\
Isometric post test & 0.641 & 8 & 0.000 \\
Isotonic pre test & 0,000 & 6 & 0,000 \\
Isotonic post test & 0.641 & 8 & 0.000 \\
Control pre test & 0,000 & 8 & 0,000 \\
Control post test & 0.000 & 7 & 0.000 \\
\hline
\end{tabular}

The following table shows that the test uses Shapiro-Wilk because the number of respondents is less than 50 and has a significance value of 0.000 , which means that the data has an abnormal data distribution because it has a significance value of 0.000 , this is because the $\mathrm{p}$ value is less than 0.05 . The following table shows the analysis The statistic has a significance value of 0.000 on isometric exercise which indicates an increase in the provision of exercise. Meanwhile, the control group has a significance value of 1,000 , which means that there is no relationship between the provision of intervention.

\begin{tabular}{cccc}
\multicolumn{2}{c}{ Intervention } & $\mathbf{N}$ & Asymp. Sig. (2-tailed) \\
\hline \multicolumn{2}{c}{ Isometric pretest - post test } & 15 & 0,000 \\
\multicolumn{2}{c}{ Isotonic pretest - post test } & 15 & 0,000 \\
\multicolumn{2}{c}{ Control pretest - post test } & 15 & 1,000 \\
\hline Intervention & $\mathbf{N}$ & Mean Rank & Asymp. Sig. (2-tailed) \\
\hline Isotonic & 15 & 27.67 & 0,000 \\
Isometric & 15 & 28.60 & 0,000 \\
Control & 15 & 12.73 & 0,000 \\
\hline
\end{tabular}

Table 3: statistical test

Based on table 3 , it shows that the statistical analysis has a significance value of 0.00 , which means that the 3 exercises have different effects. To determine which result is the most effective, the mean rank of each exercise has different values, namely: isotonic exercise has a value of 27.67; isometric; 28.60; and control 12.73. The conclusion that can be concluded that the value of isometric training has the highest value, namely 28.60 which means it is the most effective exercise to increase the value of MMT.

\section{DISCUSSION}

The occurrence of Knee osteoarthritis deformity of the progressive degradation of the joint cartilage and surrounding tissues including muscles, bones and ligaments is characteristic of histopathological changes in osteoarthritis. Edema and degradation of the molecular structure of the joint cartilage reduce the ability of this tissue to lower the load passing through the knee or reduce friction in the joint during movement. In addition, this condition is also accompanied by subchondral skeletal bone, ligamentous laxity, and decreased muscle function causing the disease to progress chronically. The risk factors for this process are old age, women, obesity, muscle weakness and a history of trauma. The initiator of this pathological process is thought to be mechanical stress, which causes a process of tissue destruction that takes place faster than the body's ability to repair it. (Felson, et al, 2014).

Osteoarthritis is the result of the failure of chondrocytes to maintain a balance between degradation and extracellular matrix synthesis. Various proteinases such as matrix metalloproteinases also play a role in the process of cartilage destruction. In addition, proinflamatory cytokines that are synthesized by chondrocytes and synoviocytes can trigger the production of enzymes that cause cartilage degradation. Other inflammatory mediators including prostaglandins and reactive oxygen types also contribute to the pathogenesis of osteoarthritis.

Mechanical factors are very important in cartilage homeostasis and mechanical stress plays a significant role in the occurrence of disease and its progression. There are several mechanisms that cause mechanical stress on joints. Often begins an injury to a joint whose protective mechanism is not good. Joint protection includes: joint capsule, ligaments, muscles, sensory afferents and the bones therein. 
The joint capsule and ligaments protect the joint by limiting the excursion, thereby fixing the joint scope. Synovial fluid reduces friction between the surfaces of the articular cartilages, serving as the main protection against friction on the cartilages. The function of lubrication depends on the lubricin molecule, a mucinous glycoprotein secreted by synovial fibroblast cells whose concentration decreases after joint injury or during joint inflammation. (Fauci, et al, 2018).

The muscles and tendons apply the appropriate tension on the excursion of the joint to protect the joint and anticipate the load going through it. The focal stress that passes through the joint is minimized by muscle contraction which reduces the impact on the joint. The bone under the cartilage can also function as a shock absorbent. Failure of this joint protective mechanism will increase the risk of joint injury and Osteoarthritis (Fauci, et al, 2018).

Based on this diagram, it can be concluded that Osteoarthritis is more about women. Women are at high risk for knee osteoatritis due to levels of the hormone estrogen. The relationship between estrogen and bone formation and the prevalence of Osteoarthritis in women suggests that hormones have an active role in the development and progression of this disease. Women who have experienced menopause will experience a decrease in estrogen. Estrogen affects osteoblasts and endothelial cells. If there is a decrease in estrogen, the TGF- $\beta$ produced by osteoblasts and nitric oxide (NO) produced by endothelial cells will also decrease, causing osteoclast differentiation and maturation to increase. Estrogen also affects bone marrow stroma cells and mononuclear cells which can produce HIL-1, TNF- $\alpha$, IL6 and M-CSF so that Osteoarthritis can occur because of these inflammatory mediators. Not only that, estrogen also affects calcium absorption and calcium reabsorption in the kidneys, resulting in hypokalemia. This hypochalemic state causes a feedback mechanism thereby increasing parathyroid hormone. This increase in parathyroid hormone can also increase bone reaobsi so that it can lead to Osteoarthritis (Helmi, 2012).

Body mass index is a measurement that correlates height and weight, according to Gibson in Dekurniati, 2016 body mass index is used to determine the value of a person's nutritional status in determining the standard proportion of body composition in children, adolescents, and adults. Obesity is one of the risk factors for knee Osteoarthritis. The knee joint is the support of half a person's body weight during walking. Obesity carrying heavier loads will make the joints work harder, thought to contribute to Osteoarthritis. As well as obesity causes abnormal mechanical stress, thereby increasing the risk of developing Osteoarthritis (Helmi, 2012).

Research conducted by Abdurachman 2019 entitled the effect of isometric training on the functional abilities of elderly people with osteoarthritis, which shows the results that isometric exercises can improve the functional abilities of elderly people with knee Osteoarthritis.

Knee osteoarthritis is a process of progressive degradation of the joint cartilage and tissues around the joints including muscles, bones and ligaments (Felson, et al., 2014). Muscles provide the strength needed to move the synovial joint. Muscles act as stabilizers in the relationship with or between joints and the structures surrounding the joints. Changes in muscle strength or integrity can affect joint function and are an important foundation in the Osteoarthritis joint (Roos, et al; 2011). Pain in knee osteoarthritis is closely related to decreased muscle strength around the knee because immobilization for a long time causes disuse atrophy and reduced muscle strength by $3 \%$ in one week (Roos, et al, 2011).

The decrease in quadriceps muscle strength in patients with knee osteoatritis is a physiotherapy problem that can be overcome by isomertic exercises which aim to increase the strength of the lower leg muscles, especially the Quadriceps muscle. Isometric training is a form of static training that causes muscles to contract and generate force without any change in muscle length and without any changes in the joints involved. Isometric exercises to control the neuromuscular quadricep femoris muscle and the dynamic stability of the knee muscles (Kisner \& Colby, 2013).

This research is supported by research conducted by Utami 2019 entitled the effect of isotonic training on functional improvement in patients with knee Osteoarthritis, indicating that isotonic exercise can improve functional abilities in patients with knee Osteoarthritis. Another study that shows the results that support this study is a study conducted by Rafique 2013 entitled the effectiveness of isotonic training to increase quadriceps muscle strength in patients with knee Osteoarthritis, which shows that isotonic exercise has an effect on increasing quadriceps muscle strength.

Quadriceps isotonic exercises if done regularly will increase blood circulation so that metabolism will increase and there will be an increase in the diffusion of fluids in the joints through the bone matrix. The strong contraction of the quadriceps muscle as a result of isotonic quadriceps exercise will facilitate the pumping action process so that the local metabolism and circulation processes can take place properly because of vasodilation and relaxation after the maximum contraction of the muscle (Susilowati, 2015) The pumping action process of isotonok exercise will facilitate the transport of metabolic waste (substance $\mathrm{p}$ ) and acetabolic produced through the inflammatory process so that pain 
will be reduced. Less pain will increase the movement in the knee joint can increase muscle strength in knee osteoarthritis (Susilowati, 2015).

The results of statistical tests in this study which examined the differences between isometric exercises and isotonic exercises showed that isometric exercises were the most effective exercises to increase the Manual Muscle Training value. The research conducted by Utami 2019, entitled the difference in the effect of quadriceps isometric training and isotonic quadriceps exercise on increasing functional ability in knee osteoarthritis, found that there was no difference in the effect of isometric training and isotonic quadriceps exercise on functional improvement in patients with knee Osteoarthritis.

The quadriceps play an important role in passing the load across the knee joint. The quadriceps muscle is the main extensor muscle of the knee joint which is very important for maintaining stability and function of the knee joint (Syaifuddin, 2013). The mechanism of action of this quadriceps is needed, such as when walking, the quadriceps muscle provides control of knee flexion during initial contact (loading response) then extension of the knee for midstance then pressing heel-off to toe off during walking activities and in maintaining knee joint function when performing closed-kinetic chain movements. to lift or lower the body, and if the function of the quadriceps muscles is disturbed, of course the control of these movements cannot be done properly (Kisner and Colby, 2013). Past research has shown that quadriceps muscle weakness is a factor more associated with disability than the radiological severity of osteoarthritis. Other studies have stated that reduced strength, especially in the quadriceps muscles, is a risk factor for the onset and progression of knee osteoarthritis, due to the reduced ability of the muscles to control joint movement accurately (Roos, et al; 2011).

\section{CONCLUSION}

There is a difference in the effect of giving isometric and isotonic exercises, namely that the provision of isometric exercises is more effective than isotonic exercises in increasing the strength of the quadriceps femoris muscles in patients with knee osteoarthritis in Singgasana Rama Physiotherapy Clinic.

Thanks to:

1. Singgasana Rama Blitar Physiotherapy Clinic, which has provided the opportunity for research.

2. Respondents who have participated in the research from start to finish, thank you for your time and effort.

3. Singgasana Rama Blitar Physiotherapy Clinic employees who helped the research

\section{Conflict of Interest}

The researcher stated that there was no conflict of interest whatsoever in this study.

\section{REFERENCES}

Anthony S. Fauci, 2008. Harrison's Internal Medicine, 17th Edition, USA, McGraw-Hill, pages 1586 $-1593$.

Anwer, S., \& Alghadir, A. 2014. Effect of Isometric Quadriceps Exercise on Muscle Strength, Pain, and Function in Patients with Knee Osteoarthritis: A Randomized Controlled Study. Journal of Physical Therapy Science, 26 (5), 745-748.https://doi.org/10.1589/jpts.26.745

Azka Hayati 2014. Effect of Exercise Therapy Effect of Light and Medium Intensity Quadriceps Muscles on Knee OA Patients. Thesis Jakarta University of Indonesia

David T Felson, Joyce Goggins, Jingbo Niu, Yuqing Zhang, David J Hunter. 2004. The Effect of Body Weight on Progression of Knee Osteoarthritis Is Dependent on Alignment,https://pubmed.ncbi.nlm.nih.gov/15593215/

Helmi, ZN 2012. Textbook of Musculoskeletal Disorders, Jakarta, Salemba.

Kerlinger. 2012. Behavior Research Principles. Edition 3, Printing 7. Yogyakarta: Gadjah Mada University Press.

Kisner, C and Colby LA 2013. Therapeutic Exercise: Foundations and Techniques. 5th Ed. Philadelphia: FA Davis Company. PP: 2

Meiliasary. 2013. The Effect of Isotonic Exercises with the Resistance Training Method on Pain due to Muscle Factors in Knee Osteoarthritis. Publication manuscript. muhammadiyah Surakarta university 
Roos EM, Roos HP, Lohmander LS, Ekdahl C, Beynnon BD. 2011. Knee Injury and Osteoarthritis Outcome Score (KOOS): development of a self-administered outcome measure. J Orthop Sports Phys Ther.; 28: p. 88-96

Syaifuddin, H. 2013. Physiological Anatomy: Competency-Based Curriculum for Nursing \& Midwifery. 4th Edition Jakarta: EGC 